\title{
Winter thunderstorms in Kamchatka
}

\author{
Sergey Smirnov ${ }^{1, *}$, Yury Mikhailov ${ }^{2}$, Galina Mikhailova $^{2}$, and Olga Kapustina ${ }^{2}$ \\ ${ }^{1}$ Institute of Cosmophysical Researches and Radio Wave Propagation FEB RAS, Paratunka, Kam- \\ chatsky Kray, Russia \\ ${ }^{2}$ Pushkov Institute of Terrestrial Magnetism, Ionosphere and Radio Wave Propagation RAS, Moscow, \\ Russia
}

\begin{abstract}
Winter thunderstorms in Kamchatka are rare meteorological phenomena. To investigate the nature of this phenomenon, time variations of quasistatic electric field and meteorological quantities at «Paratunka» observatory, IKIR FEB RAS $\left(\varphi=52.97^{\circ} \mathrm{N} ; \lambda=158.25^{\circ} \mathrm{E}\right)$, and the data on solar, seismic and cyclonic activities available in INTERNET were used as a thunderstorm activity indicator. It was shown that powerful solar flares accompanied by radiation increases in visible and infra-red spectra as well as the Earth infra-red radiation entering the atmosphere before powerful earthquakes with magnitude $\mathrm{M}>8$ may be additional sources of heat in the near-ground atmosphere of Kamchatka. The impact of tropical cyclones on the processes of thunderstorm activity formation in Kamchatka during weak seismic activity has been determined insufficiently and requires further detailed investigation.
\end{abstract}

\section{Introduction}

Winter thunderstorms in Kamchatka are very rare meteorological phenomena which are observed once or twice within five-year period, according to some sources, and within two-year period, according to others. Meteorologists associate this phenomenon with the peculiarities of local climate which differs by significant instability determined by the surrounding sea influence, constant motion of air masses due to air pressure changes and the effect of cyclones arriving from the Pacific Ocean. Tropical cyclones bring warm and humid air to the peninsular causing continuous heavy showers in summer and snow storms in winter. In spite of high cyclonic activity, the average number of thunderstorm days per year in the peninsular is 10.8 according to the data (https://yandex.ru/pogoda/paratunka/month).

Consequently, besides cyclones, impact of other sources of additional thermal energy, penetrating into the near-ground atmosphere to form thunderstorm clouds, is also possible. Indeed, in the papers $[1,2]$ it was discovered that thunderstorm processes appeared after powerful solar flares accompanied by solar radiation increase in spectrum visible and infrared ranges. Moreover, the authors [3] also found thunderstorm phenomena 6-7 days before strong earthquakes with magnitude $M>8$.

This paper is devoted to a detailed analysis of winter thunderstorm occurrences in Kamchatka, including simultaneous records of quasi-static electric field strength and meteorological quantities as well as solar, cyclonic and seismic activity data to estimate their contribution into the development of thunderstorm processes in the near-ground atmosphere.

\footnotetext{
*e-mail: serget@ikir.ru
} 


\section{Initial experimental data}

As an indicator of thunderstorm activity we considered diurnal variations of quasi-static electric field strength (Ez-component) simultaneously with meteorological quantity variations in the near-ground atmosphere at «Paratunka» FEB RAS observatory $\left(\varphi=52.97^{\circ} \mathrm{N}\right.$; $\lambda=158.25^{\circ} \mathrm{E}$ ). Electric field strength was measured by «Pole-2» device with time sampling rate of $1 \mathrm{~min}$. Meteorological quantities (temperature $T^{\circ} \mathrm{C}$; pressure $\mathrm{P}, \mathrm{hPa}$; relative humidity $\mathrm{Hm}, \%$; precipitation, $\mathrm{mm}$ and wind velocity V, m/s) were measured by WS-2000 and WS2300 digital stations with time sampling rate of $10 \mathrm{~min}$. To estimate the level of solar activity, we used the records of X-ray fluxes (X-rays, $W / m^{2}$ ) [http://www.staff.oma.be/default.jsp], seismic activity [http://www.isc.ac.uk/iscbulletin/search/catalogue/interactive/], cyclonic activity in the Pacific Ocean area [http://agora.ex.nii.ac.jp/digital-typhoon/search.date.html.en]. Winter thunderstorms are not long that is why they are not always displayed in meteorological data which at local sites are traditionally measured every three hours within a day or as their averaged diurnal values [https://yandex.ru/pogoga/paranunka/month]. Compared to those methods, their records are almost continuous (every $10 \mathrm{~min}$ ) at «Paratunka» observatory. Thus, detailed records of time variations of electric field strength and meteorological quantities allow us to estimate thunderstorm activity state in the near-ground atmosphere accurately and reliably. On time records of electric field strength, thunderstorm processes manifest as sign-variable oscillations of high value of the order $\mathrm{kV} / \mathrm{m} \mathrm{[4]} \mathrm{in} \mathrm{contrast} \mathrm{to} \mathrm{the}$ regular oscillations in «fair weather» conditions $(\sim 100 \mathrm{~V} / \mathrm{m})$ and intensity bay-like decreases before earthquakes [5]. In the following pages we consider the features of these quantities for the events of anomalously strong earthquakes with magnitude $M>8$ (November 2006 and January 2007) and powerful solar flares (October 2003 and November 2004).

\section{Main results}

Events in November 2004. The peculiarity of these events is that they developed at the background of powerful solar flares accompanied by two magnetic storms [1]. That caused excitation of anomalously strong thunderstorm processes in the near-ground atmosphere in Kamchatka. Fig. 1a shows diurnal variations of electric field Ez-component and meteorological quantities (temperature $T^{\circ} \mathrm{C}$, air pressure $\mathrm{P}, \mathrm{hPa}$, relative humidity $\mathrm{Hm}, \%$ and wind velocity $\mathrm{V}, \mathrm{m} / \mathrm{s})$ and X-rays $\left(\mathrm{W} / \mathrm{m}^{2}\right)$ within the period from November 4 to 14,2004 . As it is clear, from November 4 to 9 , high solar activity with anomalous X-ray fluxes $\left(\sim 10^{-4} \mathrm{~W} / \mathrm{m}^{2}\right)$ was observed. As it was known, it was accompanied, by radiation flux increases in visible and infra-red ranges. It is obvious on the temperature and relative humidity graphs that it caused distortion of their regular diurnal variation on November 3 and 4 . In the result of solar flare impact, the temperature raised from minus $15^{\circ} \mathrm{C}$ to zero and positive values at nighttime and relative humidity increased to 80 and more percents. That caused generation of thunderstorm activity on November 7 and 10 (characteristic sign-variable oscillations of electric field Ez component). Within this period, the cyclone activity in the Pacific Ocean area was calm, typhoon MUIFA (Fig. 1b) was generated only on November 14 very far from Kamchatka. It is possible that its power and duration (of more than 10 days) are determined by solar activity increase on the preceding days. Seismic activity during this period (Table 1) was also relatively calm. Earthquake times are shown by arrows on the $\mathrm{x}$-axis of Ez component on which there are no events caused by earthquakes.

Finishing the analysis of the figure graphs and cyclonic and seismic activity state, we can definitely make the conclusion that thunderstorm activity in November was caused by solar activity increase during that period. 

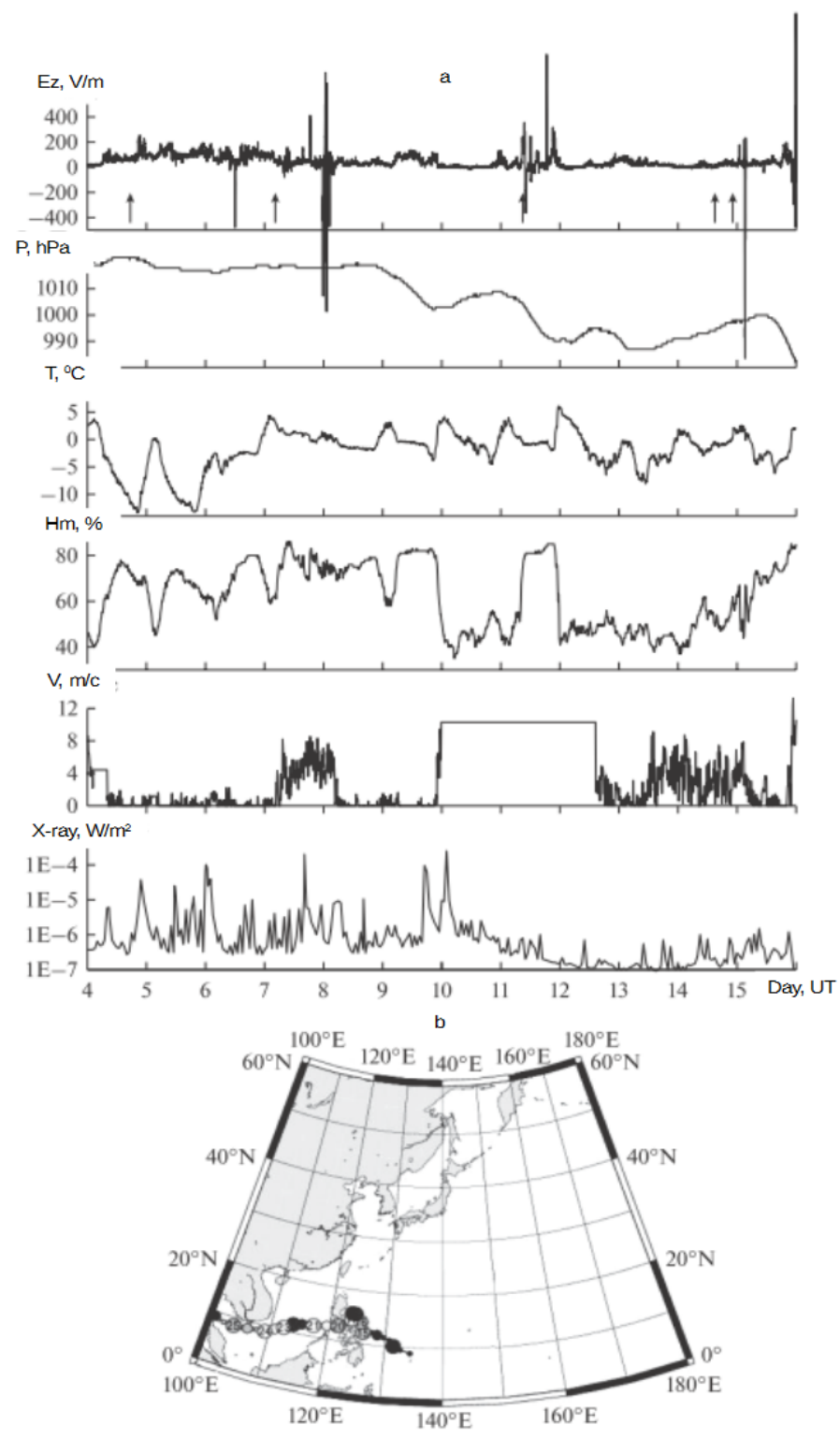

Figure 1. Diurnal variations of quasi-static electric field Ez component in the near-ground atmosphere of Kamchatka, meteorological quantities and solar X-ray fluxes (in the range of 0.1-0.8 nm) in November 2004 (a); MUIFA typhoon track (b).

Events in October 2003. The effects in the near-ground atmosphere, considered below, developed during anomalous increase of solar activity on October 21-31 (Fig. 2a), when X-ray radiation fluxes reached anomalous values of the order of $10^{-3} \mathrm{~W} / \mathrm{m}^{2}$ during the flares. In that case, radiation fluxes in the spectrum visible part also increased [6]. Inflow of additional thermal energy caused noticeable distortion of temperature regular diurnal variation on October 21 and 22 increasing negative nighttime values $\left(-3^{\circ} \mathrm{C}\right)$ to positive values $\left(+4-5^{\circ} \mathrm{C}\right)$. Within 
Table 1. Earthquakes near Kamchatka in November 2004.

\begin{tabular}{|c|c|c|c|c|c|c|c|}
\hline $\mathbf{N}$ & Date & Time & $\varphi^{\circ} N$ & $\lambda^{\circ} E$ & $\mathbf{h , ~ k m}$ & $\mathbf{M}$ & $\mathbf{R , ~ k m}$ \\
\hline 1 & 04.11 .2004 & $14: 03: 11.74$ & 43.665 & 146.812 & 62.4 & 5.8 & 312 \\
\hline 2 & 07.11 .2004 & $02: 02: 26.34$ & 47.884 & 144.486 & 481.8 & 6.1 & 420 \\
\hline 3 & 11.11 .2004 & $10: 02: 47.12$ & 42.164 & 144.331 & 32.2 & 6.1 & 420 \\
\hline 4 & 14.11 .2004 & $17: 37: 42.42$ & 41.777 & 144.114 & 15.0 & 5.1 & 156 \\
\hline 5 & 14.11 .2004 & $17: 57: 40.66$ & 41.781 & 144.064 & 30.3 & 5.0 & 140 \\
\hline 6 & 14.11 .2004 & $18: 44: 13.62$ & 41.786 & 144.079 & 21.0 & 5.4 & 210 \\
\hline
\end{tabular}

the periods of October 23-27 and 29-31, air high humidity ( 90\%) remained unchanged. That caused generation of intensive and lasting thunderstorm activity on October 24 and 30 (Ez component strength variations, strong winds, heavy precipitation). Just on these days, maximum intensity of PARMA typhoon was observed (Fig. 2b) when the minimum pressure in the «eye» was $930 \mathrm{hPa}$ and the maximum velocity was $95 \mathrm{knots} / \mathrm{h}$. This powerful typhoon was generated on October 21 at $\varphi \sim 20-35^{\circ} \mathrm{N}$ and moved along the latitude from $140^{\circ}$ to $180^{\circ} \mathrm{E}$ within 10 days. Less powerful typhoon KETSANA ( $\mathrm{V}=90 \mathrm{knots} / \mathrm{h} ; \mathrm{P}=940 \mathrm{hPa}$ ) was simultaneously active within the same period on October 19-26 in the Pacific Ocean area (Fig. 2c) [http://agora.ex.nii.ac.jp/digital-typhoon/search.date.html.en]. Chronological order of their motion is illustrated in the pressure graph of Fig. 2a. Simultaneous development of these typhoons caused by anomalous solar flare occurrences allowed us to make the conclusion that only super-powerful typhoons are capable of causing thunderstorm processes in winter time in the near-ground atmosphere of Kamchatka. Seismic activity during this period was relatively calm $(M \sim 5)$. Earthquake characteristics are illustrated in Table 2 and the time instants are marked by arrows in Ez component graph. They were preceded by electric field strength bay-like decreases of significantly less intensity compared to the oscillations during thunderstorm activity.

Table 2. Earthquakes near Kamchatka in October 2003.

\begin{tabular}{|c|c|c|c|c|c|c|c|}
\hline $\mathbf{N}$ & Date & Time & $\varphi^{\circ} N$ & $\lambda^{\circ} E$ & $\mathbf{h}, \mathbf{k m}$ & $\mathbf{M}$ & $\mathbf{R}, \mathbf{k m}$ \\
\hline 1 & 23.10 .2003 & $10: 54: 37.10$ & 51.76 & 176.39 & 14 & 5.3 & 190 \\
\hline 2 & 23.10 .2003 & $10: 54: 39.70$ & 51.46 & 176.56 & 33 & 5.3 & 190 \\
\hline 3 & 23.10 .2003 & $15: 32: 06.18$ & 51.39 & 176.55 & 33 & 5.1 & 156 \\
\hline
\end{tabular}

Events in November 2006 and January 2007. These events are associated with strong Kuril earthquakes the magnitude of which exceeded the value $M \sim 8$ (Table 3, and the chronological order is indicated by arrows in Ez component graph in Fig. 3a and 4) [3]. It is clear on the temperature $T^{\circ} \mathrm{C}$ graphs that «fair weather» conditions with temperature regular diurnal variation and relative humidity $\mathrm{Hm}, \%$ changed from November 8 and January 5. When humidity was high $(\sim 90 \%)$, temperature gradually increased within several days up to the time of a strong earthquake. On some days, temperature growth was accompanied by wind increase $(V \sim 18-25 \mathrm{~m} / \mathrm{s})$ and development of powerful thunderstorm activity (November 8 and 13 and January 7-8). Moreover, on November 13 thunderstorm activity effects were observed in electric field variations. They coincided with bay-like decrease of field strength determined by the strong earthquake on November 15 . Solar activity during these periods was relatively calm, X-ray fluxes were of the order of $10^{-6} \mathrm{~W} / \mathrm{m}^{2}$. Cyclonic activity was also very low. CHEBI typhoon was generated at the latitude below $20^{\circ} \mathrm{N}$ and moved for four days (November 9-13) within the longitude interval of $115-135^{\circ} \mathrm{E}$ with maximum wind velocity of $\sim 100$ knots/h (Fig. 3b) [http://agora.ex.nii.ac.jp/digital-typhoon/search.date.html.en], i.e. 


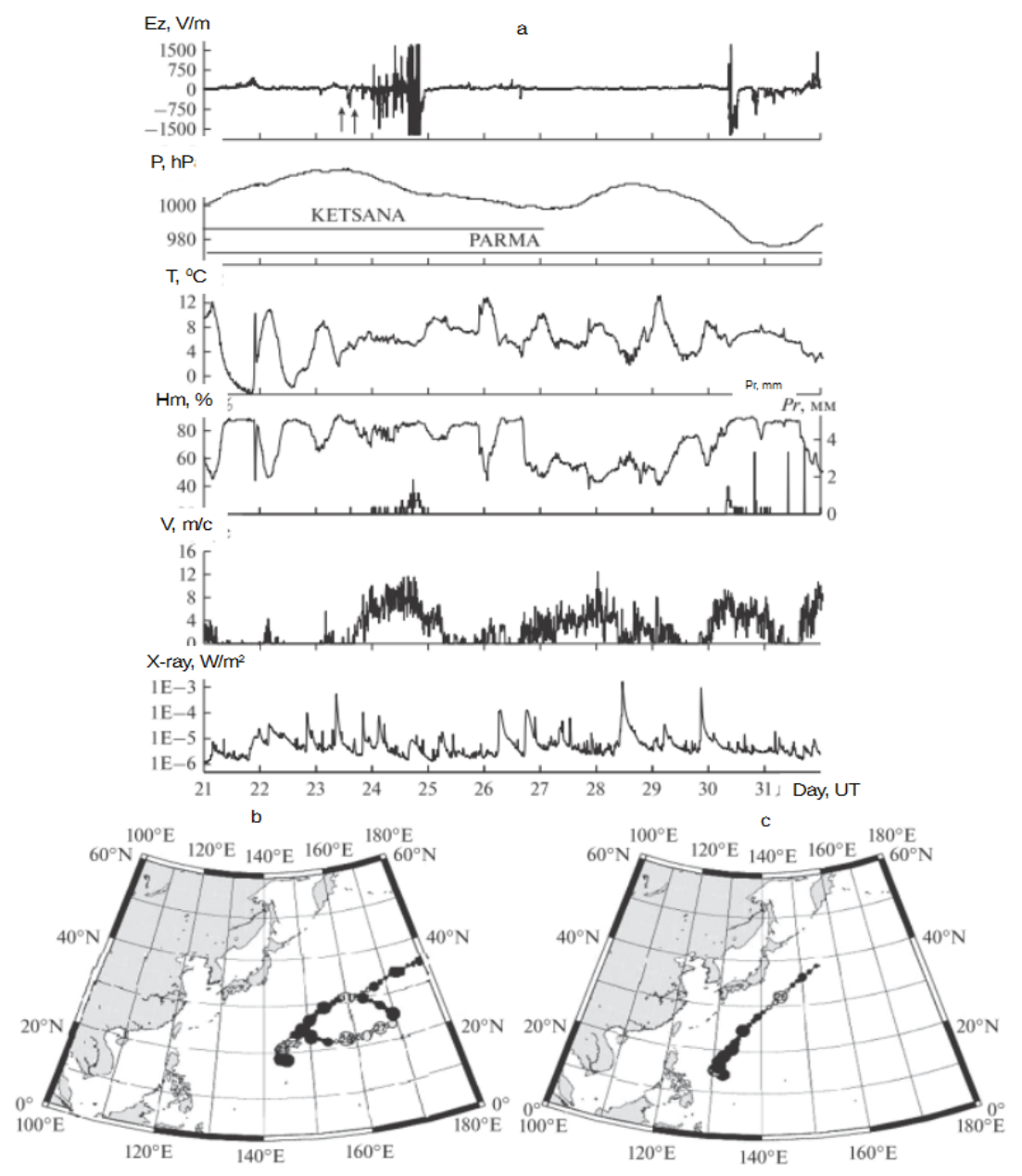

Figure 2. The same as in Fig. 1 but in October 2003 (a); PARMA (b) and KETSANA (c) typhoon tracks.

it was far away from Kamchatka. During the January period, neither typhoons nor storms were observed in the Pacific Ocean area under consideration. Thus, in spite of the negative regular trend during this time of the year [3], the detected temperature anomalous growth was caused, to our mind, by the appearance of an additional heat source. The state of solar, seismic and cyclonic activity allows us to make the conclusion that this source is of seismic nature.

\section{Discusion and conclusions}

As it follows from meteo-service archives [www.pogodaiklimat.ru], winter thunderstorms occur very rarely in Kamchatka. For the thunderstorm activity to be generated during this time, thermal energy from the Sun is not enough. And for the cumulo-nimbus and cumulothunderstorm clouds to be formed, the following conditions are necessary, they are: warm air convection, high moisture content and instability in the troposphere in the result of heavy 


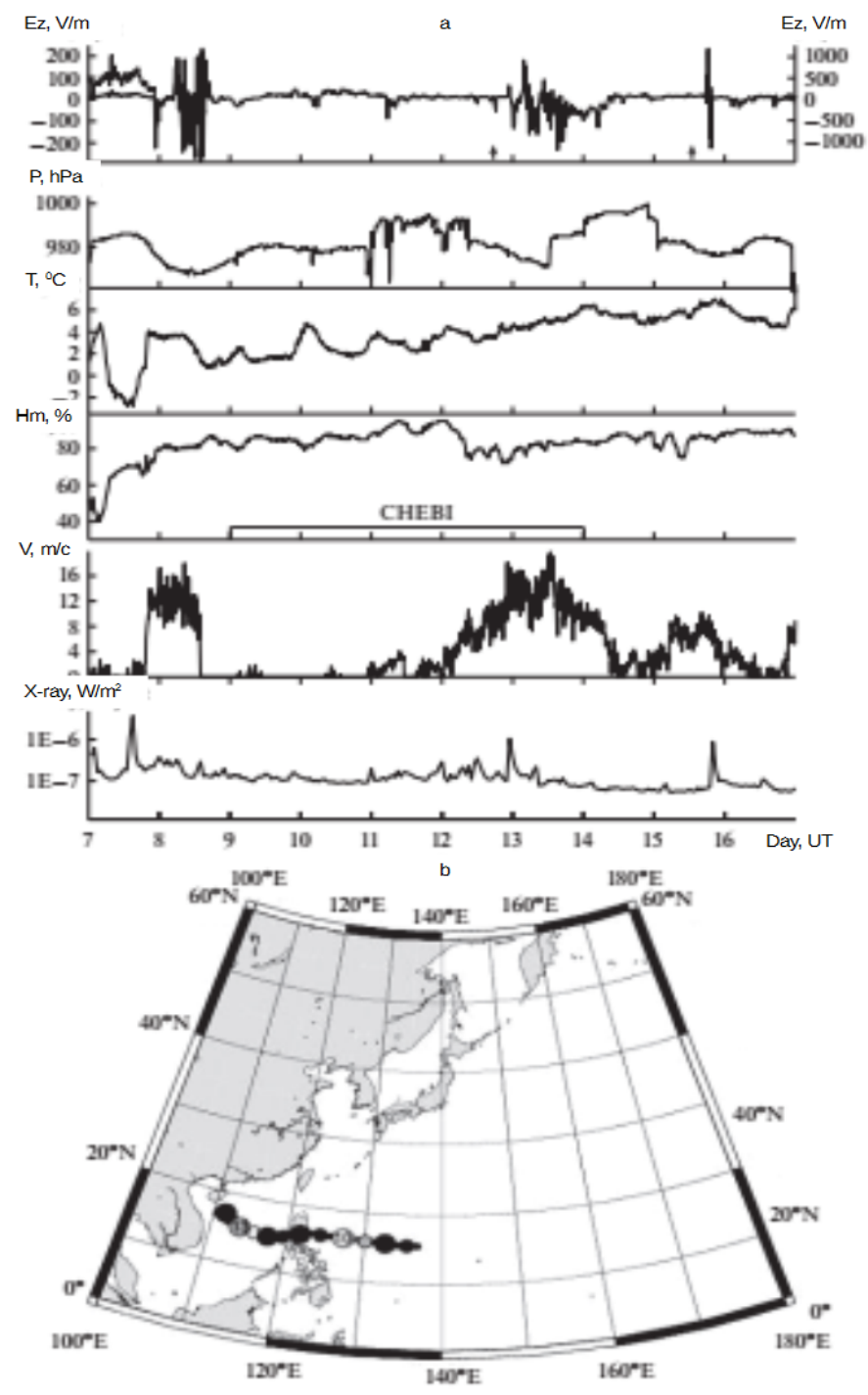

Figure 3. The same as in Fig. 1 but in November 2006 (a); CHEBI typhoon track (b).

height temperature gradient [7]. At the first stage of this process, cumulus clouds are formed with heavy precipitation and winds. Then they develop into more powerful cumulus and cumulus-thunderstorm clouds with lightning discharges. These stages are clearly observed in time variations of meteorological quantities (Fig. 1-4). It is obvious that the trigger mechanism for this process is the moment of air temperature increase followed by upward motion, i.e. for thunderstorm activity to develop, an additional source of thermal radiation in the nearground atmosphere is required. Meteorologists think that cyclones are such a source. They bring warm and humid air to the peninsula in winter causing temperature instability in the troposphere. As it follows from weather archives, tropical cyclones occur quite often especially during autumn and winter seasons when the ocean surface is warmed up to high temperatures and water evaporation increases. At the same time, winter thunderstorms occur very rarely. 
Table 3. Earthquakes near Kamchatka in November 2006 and January 2007.

\begin{tabular}{|c|c|c|c|c|c|c|c|}
\hline $\mathbf{N}$ & Date & Time & $\varphi^{\circ} N$ & $\lambda^{\circ} E$ & $\mathbf{h , ~ k m}$ & $\mathbf{M}$ & $\mathbf{R , ~ k m}$ \\
\hline 1 & 12.11 .2006 & $14: 42: 24$ & 55.164 & 165.295 & 37.4 & 5.0 & 140 \\
\hline 2 & 15.11 .2006 & $11: 14: 13.57$ & 46.592 & 153.266 & 30.3 & 8.3 & 3706 \\
\hline 3 & 08.01 .2007 & $16: 23: 38.00$ & 54.297 & 159.170 & 136.5 & 4.6 & 95 \\
\hline 4 & 11.01 .2007 & $04: 27: 26.32$ & 60.955 & 165.478 & 10.0 & 5.0 & 140 \\
\hline 5 & 13.01 .2007 & $04: 23: 21.16$ & 46.243 & 154.524 & 10.0 & 8.1 & 3040 \\
\hline 6 & 13.01 .2007 & $17: 35: 22.51$ & 54.796 & 166.192 & 10.0 & 4.9 & 127 \\
\hline 7 & 13.01 .2007 & $17: 37: 06.31$ & 46.913 & 156.276 & 10.0 & 6.0 & 380 \\
\hline
\end{tabular}

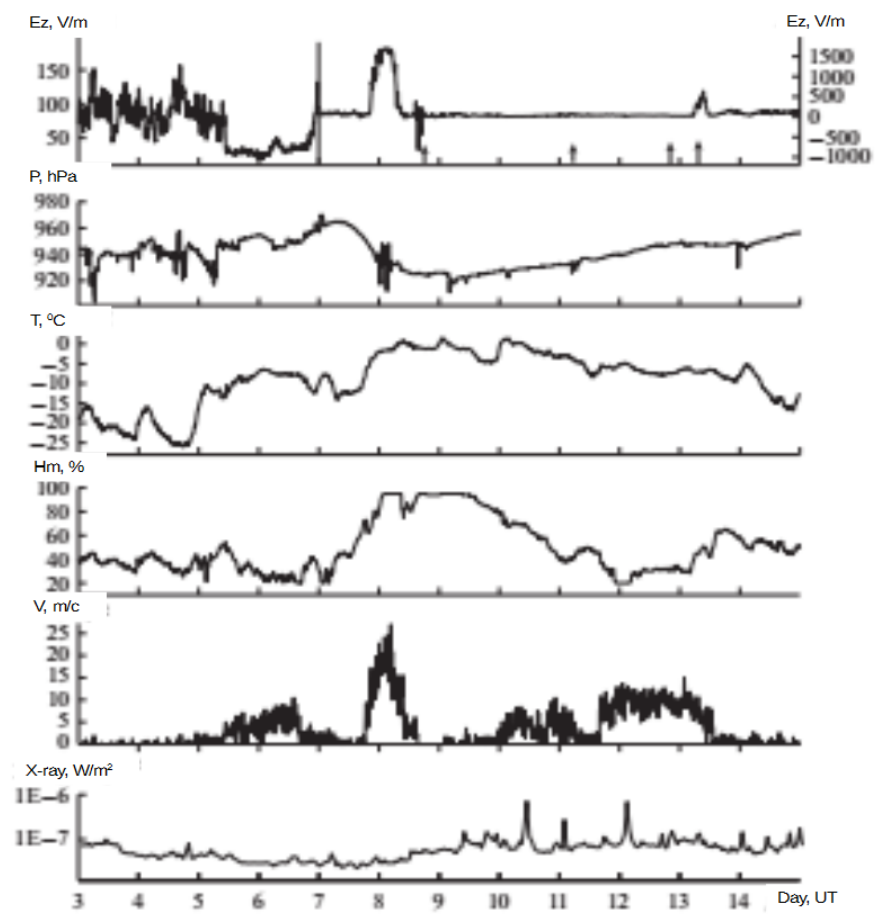

Figure 4. The same as in Fig. 1 but in January 2007.

Consequently, the thermal energy brought by cyclones is not always enough for thunderstorm activity to be generated and additional source of thermal radiation in the near-ground atmosphere is required. Comparative analysis of the data of electric and meteorological quantities, seismic and cyclonic activity allowed us to distinguish these additional sources. It turned out that during strong solar flares, like those occurred in 2003 and 2004 and occurring not often, heat flux in visible and infrared ranges arises $[6,8]$. It is enough for the thunderstorm activity to be generated. Moreover, it is known [9] that seismic processes in the Earth's crust before powerful earthquakes with magnitude $\mathrm{M}>8$ may be an additional source of heat in infrared range. They occur in very rare cases. In our case, the both sources acted during weak or powerful cyclonic activity the role of which was evidently reduced to the appearance of temperature instability in the troposphere. The issue of winter thunderstorms in Kamchatka 
during strong tropical cyclones but during weak solar and seismic activities requires further detailed investigation.

\section{Acknowledgements}

The authors appreciate «Paratunka» observatory IKIR FEB RAS.

\section{References}

[1] S.E. Smirnov, G.A. Mikhailova, O.V. Kapustina, Geomagnetism and Aeronomy 53, 502514 (2013)

[2] S.E. Smirnov, G.A. Mikhailova, O.V. Kapustina, Geomagnetism and Aeronomy 54, 240247 (2014)

[3] S.E. Smirnov, G.A. Mikhailova, Yu.M. Mikhailov, O.V. Kapustina, Geomagnetism and Aeronomy 57, 610-617 (2017)

[4] G.A. Mikhailova, Y.M. Mikhailov, O.V. Kapustina, S.E. Smirnov, Geomagnetism and Aeronomy 50, 814-823 (2010)

[5] S. Smirnov, Nat. Hazards Earth Syst. Sci. 8, 745-749 (2008)

[6] I.S. Veselovsky, et al., Cosmic Res. 42, 433-435 (2004)

[7] A.T. Matveev, Fizika atmosfery (Hidrometeoizdat, Leningrad, 2000) 778

[8] Yu.I. Yermolaev, et al., Geomagnetism and Aeronomy 45, 681-719 (2005)

[9] V.I Gorniy, et al., Earth Sci. 301, 67--69 (1988) 